\title{
Scale, Hyperscale and Metascalar Information in Living Systems
}

\author{
Ron Cottam $^{1}{ }^{*}$, Willy Ranson ${ }^{2}$ and Roger Vounckx ${ }^{1}$ \\ ${ }^{1}$ The Living Systems Project, Dept of Electronics and Informatics, Vrije Universiteit Brussel (VUB), \\ Pleinlaan 2, 1050 Brussels, Belgium \\ ${ }^{2}$ IMEC vzw, Kapeldreef 75, 3001 Leuven, Belgium \\ E-Mails: ricottam@etro.vub.ac.be; wranson@etro.vub.ac.be; rvounckx@etro.vub.ac.be
}

* Author to whom correspondence should be addressed; Tel.: +32-2-629-2933; Fax: +32-2-629-2883

Accepted:

\begin{abstract}
Investigation of the relationships between information, reality and cognition targets the structuralprocedural properties of organisms as living systems. Nature tends towards hierarchical forms of both structure and process, and consequently any study of information in this context must of necessity take account of the characteristics of existing scales and their interfaces. The situation is complicated by the pragmatic tendency of evolution to scavenge prior existing features in creating new ones, and consequently biology does not uniquely exhibit hierarchical configurations. This paper addresses the nature of hierarchical organization and the origin of information in a biological context; although the ideas presented here can be applied almost equally well to non-biological entities where hierarchy is less-well defined or extant.

We have previously published [1,2] extensive details of the relationships between different scales or levels of organization in living systems, and here we will only refer to those characteristics which are relevant to our present purpose. Dodig-Crnkovic and Giovagnoli [3] have described Nature as a hierarchically-organized network of networks, which corresponds well to our own viewpoint. Multiscalar systems are by their very nature unified, and this unification is a real characteristic of any system [4], which integrates all of the system's scales into a scale-free hyperscalar representation in which simplified replicas of the 'real' scales are 'objectively' (more-than-subjectively) accessible, in the sense that Havel [5] has (socially) defined 'objective' as a 'group subjective'. The transition from
\end{abstract}


multiple scales to their integration in hyperscale is an example of the one-out-of-many interpretation of information referred to by Schroeder [6].

Natural hierarchy decomposes into two partial hierarchies, one corresponding to the entity under consideration, the other corresponding to its context. Consequently, there are two partial integrations leading to hyperscale, and two (partial) hyperscales. These make up a ubiquitous duality in system representation. Ultimately, these two partial hyperscales re-integrate to give a singular metascalar representamen of the entire system. Peircian semiotics [7] treats all interactions as interpretations of signs. In the (biosemiotic) context of organismic system unification, individual scales, their hyperscalar representations and the metascalar outcome all appear as signs. We hypothesize that hyperscalar representations correspond to secondness in Peirce's scheme of things, and that metascale corresponds to Peirce's thirdness.

Salthe has published extensively on the concept of hierarchy [see, for example, 8]. His position has consistently been that hierarchy is a human mental construct, devoid of any other reality. We beg to differ. Hierarchy permits the generation of simple representations of complex informational domains, thus supporting faster survival-promoting reactions to environmental stimuli, and as such it is a primary cognitive mechanism used by all living systems, not just humans. This, of course, raises the question of the validity of representation in information theory. Our own position is clearly that representation is a necessary 'computational' device for survival and therefore for evolution itself. Any other position would negate the importance of hierarchy in Nature. As Dodig-Crnkovic and Giovagnoli [3] comment in their discussion of connectionist approaches, “... it is correct that there is "no computation without representation"”.

We hypothesize that the reality of a singular metascale corresponds to information per se: as Schroeder [9] points out, “...information has been formulated as identification of a variety, where identification is understood as that which either selects, distinguishes one out of many, or that which makes the many into one (a whole)." This high-level metascalar formulation incorporates the properties of all of a living system's scalar properties in such a unified form that individual selection is also possible: it combines Schroeder's [6] "two complementary manifestations of information."

\section{References}

1 Cottam, R.; Ranson, W.; Vounckx, R. Autocreative hierarchy II: dynamics - self-organization, emergence and level-changing. In International Conference on Integration of Knowledge Intensive Multi-Agent Systems; Hexmoor, H., Ed.; IEEE: Piscataway, NJ, USA, 2003, pp. 766-773.

2 Cottam, R.; Ranson, W.; Vounckx, R. A framework for computing like Nature. In Computing Nature; Dodig-Crnkovic, G., Giovagnoli, R., Eds.; Springer SAPERE series: Berlin, Germany, 2013; pp. 23-60.

3 Dodig-Crnkovic, G.; Giovagnoli, R. Computing nature - a network of networks of concurrent information processes. In Computing Nature; Dodig-Crnkovic, G., Giovagnoli, R., Eds.; Springer SAPERE series: Berlin, Germany, 2013; pp. 1-22.

4 Cottam R.; Ranson W.; Vounckx R. A biosemiotic view on consciousness derived from system hierarchy. In The Unity of Mind, Brain and World: Current Perspectives on a Science of Consciousness; Pereira Jr, A., Lehmann, D., Eds.; Cambridge University Press: Cambridge, UK, pp. 77-112. 
5 Havel, I.M. Scale dimensions in nature. International Journal of General Systems 1995, 23, 303332.

6 Schroeder, M.J. From philosophy to theory of information. Information Theories and Applications 2011, 18, 56-68.

7 Peirce, C. S. Collected Papers of Charles Sanders Peirce; Hartshorne, C., Weiss, P., Eds., Volumes 1-6; Burks, A., Ed., Volumes 7-8, Belknap Press: Cambridge, MA, USA, 1931-1958.

8 Salthe, S.N. Hierarchical structures. Axiomathes 2012, 22, 355-383.

9 Schroeder, M.J. Foundations for science of information: reflection on the method of inquiry. tripleC 2011, 9, 377-384.

(C) 2015 by the authors; licensee MDPI and ISIS. This abstract is distributed under the terms and conditions of the Creative Commons Attribution license. 